\title{
Relative uncertainties in mass attenuation coefficients and their influence on quantitative EDS and WDS analysis
}

\author{
Ralf Terborg$^{1}$, Jan Dellith ${ }^{2}$, Andy Scheffel $^{2}$, Michael Abratis ${ }^{1}$ \\ ${ }^{1 .}$ Bruker Nano GmbH, Am Studio 2D, DE-12489 Berlin, Germany \\ 2. Leibniz Institute of Photonic Technology, Albert-Einstein-Strasse 9, DE-07745 Jena, Germany
}

In quantitative energy-dispersive and wavelength-dispersive spectrometry (EDS, WDS) the absorption is often a significant factor which determines the intensity of characteristic lines. The absorption correction accounts for the fraction of generated radiation that is absorbed in the sample. For $\mathrm{K}$ lines of light elements $(\mathrm{B}-\mathrm{F})$, and $\mathrm{L}$ or $\mathrm{M}$ lines in the low-energy range it is possible that only $10 \%$ or even less of the generated characteristic radiation is emitted which has a considerable influence on the calculated result.

The absorption correction depends on the mass attenuation coefficient (MAC) for the energy of a certain characteristic radiation in the sample matrix. Therefore, the knowledge of the MACs and their uncertainties is important for the quantitative results.

There are different collections of MAC values, e.g. of Henke [1,2], Heinrich [3] or Pouchou and Pichoir [4], which show large variations for light elements, low energies and for energies close to absorption edges. E.g. L $\alpha$ lines are very close to the $\mathrm{L}_{2,3}$ absorption edges for $3 \mathrm{~d}$ transition metals and therefore introduce uncertainties.

As an example the peak intensity of the boron $\mathrm{K} \alpha$ peak in a boron containing glass standard (Duran glass) depends on the MAC for this energy, which shows variations of $~ 10 \%$ depending on the MAC database used, table 1 . WDS measurements of the $\mathrm{B} \mathrm{K \alpha}$ vs. accelerating voltage and an evaluation according to the method of Kyser [6] leads to a much lower estimation of the MAC value, fig. 1.

When using standard based quantitative EDS characteristic lines and line families are often fitted or deconvolved using standard element spectra. But in this case different absorption effects caused by different MAC values in the unknown and the standard can lead to different relative line intensities. Therefore, different line profiles can introduce errors in the peak intensity determination.

\section{References:}

[1] Henke B L, et al. Atom. Data Nucl. Data Tables 27 (1982), p. 1.

[2] Henke B L, et al. Atom. Data Nucl. Data Tables 54 (1993), p. 181.

[3] Heinrich K F J, Proc 11th Int Congr. on X-Ray Optics and Microanalysis (1986), p. 67

[4] Pouchou J L, Pichoir F, , Electron Probe Quantitation, Eds. Heinrich \& Newbury, Plenum Press N.Y., 1991, 31

[5] Llovet et al, IOP Conf. Series: Materials Science and Engineering 32 (2012), 012014

[6] Kyser, D F, Proc 6th Int Congr on X-Ray Optics and Microanalysis (Tokyo Univ Press) 1972, 147 


\begin{tabular}{|c|c|c|c|c|c|c|c|}
\hline $\begin{array}{c}\text { Data source / } \\
\text { MAC }\end{array}$ & $\mathrm{Si}$ & $\mathrm{O}$ & $\mathrm{B}$ & $\mathrm{Al}$ & $\mathrm{Na}$ & $\mathrm{K}$ & Duran glass \\
\hline $\begin{array}{c}\text { Pouchou \& } \\
\text { Pichoir 1991 }\end{array}$ & 80000 & 16500 & 3500 & 64000 & 43900 & 11300 & 41027 \\
\hline Heinrich 1986 & 83702 & 15774 & 2861 & 66069 & 40649 & 10616 & 41982 \\
\hline Henke 1982 & 84000 & 16500 & 3350 & 64000 & 43900 & 11300 & 42544 \\
\hline Henke 1993 & 86100 & 18500 & 3350 & 77300 & 45400 & 11400 & 44585 \\
\hline
\end{tabular}

Table 1: Comparison of the MACs and mean MAC according to the given composition in $\mathrm{cm}^{2} / \mathrm{g}$ for boron $\mathrm{K} \alpha$ radiation $(183 \mathrm{eV})$ for the elements and the Duran glass standard. Variations in the mean MAC show uncertainties of approximately $9 \%$.

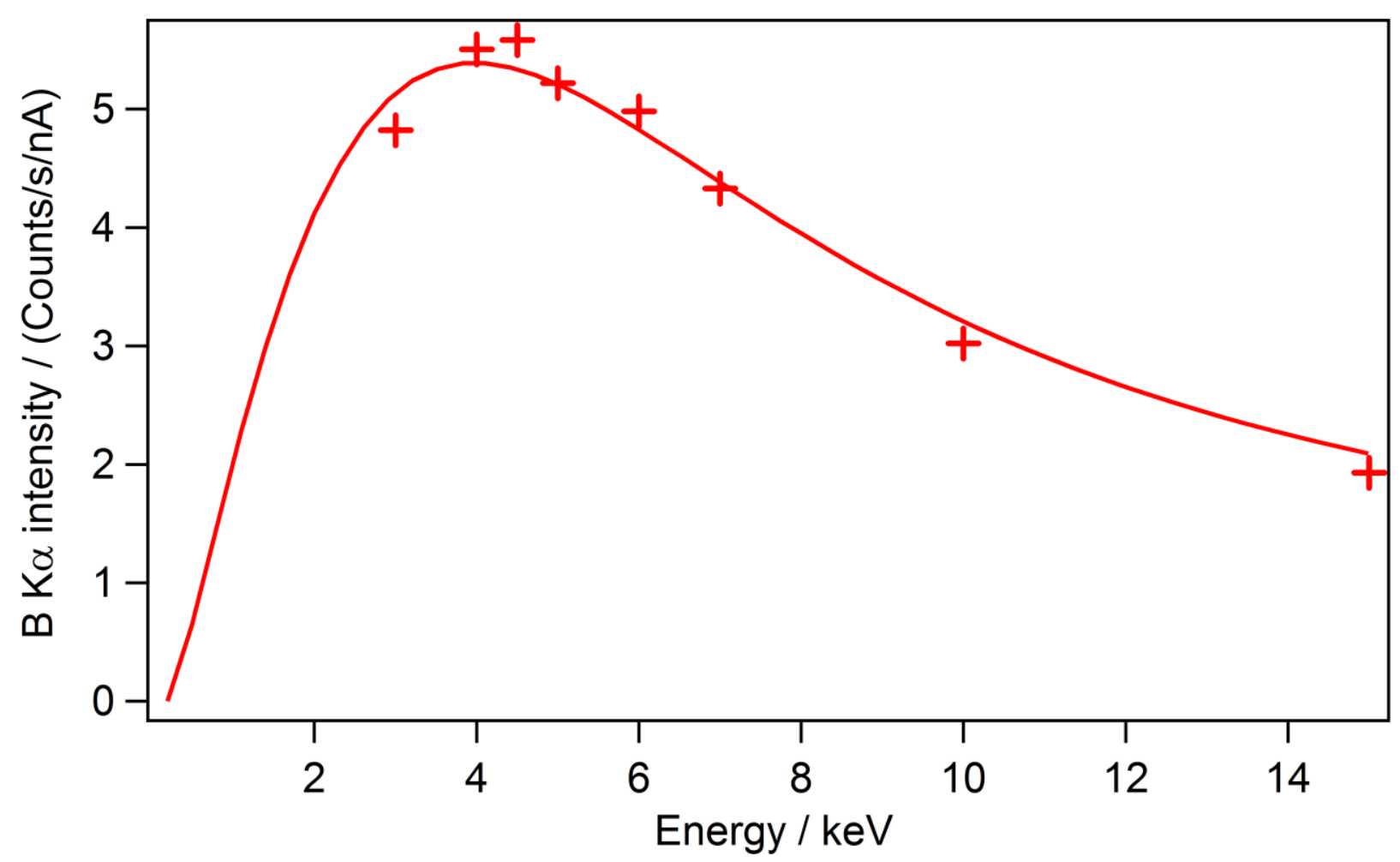

Figure 1: B K $\alpha$ WDS peak intensity vs. accelerating energy and simulation. These data can be used to estimate the MAC in a boron containing glass (Duran glass). The estimated MAC for boron $\mathrm{K} \alpha$ radiation is $30000 \mathrm{~cm}^{2} / \mathrm{g}$ using the method of Kyser [6] 